\title{
CONHECIMENTO DOS PAIS DE ADOLESCENTES SOBRE A VACINAÇÃO CONTRA O PAPILOMAVÍRUS HUMANO
}

TEENAGERS' PARENTS KNOWLEDGE ON VACCINATION AGAINST HUMAN PAPILLOMAVIRUS

CONOCIMIENTO DE LOS PADRES DE ADOLESCENTES SOBRE LA VACUNACIÓN CONTRA EL VIRUS DEL PAPILOMA HUMANO

Camila Amthauer 1

Cladiane dos Santos ${ }^{2}$

Palavras-chave:

Papillomaviridae; Doenças Sexualmente Transmissiveis; Vacinas; Prevenção Primária; Enfermagem.

Keywords:

Papillomaviridae; Sexually Transmitted Diseases; Vaccines; Primary Prevention; Nursing.

Palabras clave: Papillomaviridae; Enfermedades de Transmisión Sexual; Vacunas; Prevención Primaria; Enfermería.

Submetido: 27 de Set. de 2020

Aprovado: 16 de Nov. de 2020

Autor(a) para Correspondência: Camila Amthauer R. Oiapoc, 211 Agostini - São Miguel do Oeste, SC CEP:89900-000 Email:camila.amthauer@hotmail.com

\section{RESUMO}

Este estudo teve por objetivo identificar o conhecimento dos pais de adolescentes sobre a vacinação contra o papilomavírus humano (human papilomavirus [HPV]). Trata-se de pesquisa qualitativa, do tipo exploratóriodescritiva, realizada com 10 pais de adolescentes do sexo feminino em idade de vacinação contra o HPV. A coleta de dados ocorreu mediante entrevistas semiestruturadas, gravadas e posteriormente transcritas na integra. Os dados foram submetidos a Análise de Conteúdo do tipo temática. Constatou-se que os entrevistados apresentam conhecimento limitado, marcado por conceitos superficiais sobre vacinação. Apesar disso, os participantes se mostraram a favor da vacina por acreditarem ser uma forma de prevenção contra o HPV, principalmente por sua relação com o câncer de colo uterino. Evidenciouse a importância de investir na educação em saúde, considerando que esta assume um papel modificador na realidade de saúde da população e mostrase uma estratégia fundamental para o sucesso das campanhas de vacinação contra o HPV, com vistas à redução da infecção e transmissão pelo vírus e, consequentemente, da morbimortalidade de mulheres pelo câncer de colo uterino.

\footnotetext{
1. Aluna de Doutorado em Enfermagem na Universidade Federal do Rio Grande do Sul (UFRGS). Mestre em Enfermagem pela UfRGS. Especialista em Saúde Pública pela UFRGS. Professora na Universidade do Oeste de Santa Catarina (UNOESC).E-mail: camila.amthauer@hotmail.com ORCID: https://orcid.org/0000-0002-7530-9809

2. Enfermeira. Especialista em Unidade de Terapia Intensiva e Urgência e Emergência pelo Centro Universitário Internacional (UNINTER). Enfermeira na Secretaria Municipal de Saúde de Anchieta-SC. E-mail: cladi_2012@ hotmail.com 0RCID: https://orcid.org/0000-0002-6818-4091
}

Certificação de redação científica: E.L.Freire Editora. Edição de texto: Evandro L. Freire. Revisão de provas: Texto definitivo lido e validado pelas autoras. 


\section{ABSTRACT}

This study aimed to identify teenagers' parents knowledge on vaccination against human papillomavirus (HPV). This is a qualitative, exploratory descriptive research conducted with 10 parents of female teenagers at the HPV vaccination age. Data collection took place through semi-structured interviews, recorded and later fully transcribed. Data underwent thematic Content Analysis. It was found that respondents have poor knowledge, marked by superficial views regarding vaccination. Despite this, the participants were in favor of the vaccine because they believe it is a prevention measure against HPV, mainly because of its relation to uterine cervical neoplasms. The importance of investing in health education was evidenced, considering that it plays a modifying role in the population's health-related reality and is a key strategy for the success of HPV vaccination campaigns, with a view to reducing infection and transmission by the virus and, consequently, morbidity and mortality in women due to uterine cervical neoplasms.

\section{RESUMEN}

Este estudio tuvo como objetivo identificar el conocimiento de los padres de adolescentes sobre la vacunación contra el virus del papiloma humano (human papilomavirus [HPV]). Se trata de una investigación cualitativa, descriptiva y exploratoria, realizada con 10 padres de adolescentes del sexo femenino en edad de vacunación contra el HPV. La recolección de datos se realizó mediante entrevistas semi-estructuradas, grabadas y luego transcritas integramente. Los datos se sometieron a un Análisis de Contenido temático. Fue encontrado que los encuestados tienen un conocimiento deficiente, marcado por visiones superficiales de la vacunación. A pesar de esto, las participantes se mostraron a favor de la vacuna porque creen que es una medida de prevención contra el HPV, principalmente por su relación con las neoplasias del cuello uterino. Se evidenció la importancia de invertir en educación en salud, considerando que juega un papel modificador en la realidad sanitaria de la población y es una estrategia clave para el éxito de las campañas de vacunación contra el HPV, con miras a reducir la infección y transmisión por el virus $y$, en consecuencia, la morbilidad y mortalidad de mujeres por neoplasias del cuello uterino.

\section{INTRODUÇÃO}

0 papilomavírus humano (human papilomavirus [HPV]) é uma das doenças sexualmente transmissíveis (DST) mais frequentes, podendo ser transmitida por contato genital ou contato pele a pele ${ }^{1}$. A maioria das infeções por HPV é transitória, regredindo espontaneamente dentro de alguns meses. Em alguns casos, a infecção pode ser persistente, progredindo para lesões precursoras que, se não tratadas, podem evoluir para o câncer, principalmente de colo uterino. Outros locais podem ser acometidos, como vagina, vulva, ânus, pênis, orofaringe e boca $a^{1,2}$.

Pelo menos 13 dos mais de 150 genótipos conhecidos de HPV são considerados oncogênicos de alto risco, apresentando maior probabilidade de provocar infecções persistentes e causar lesões precursoras. 0s 2 genótipos mais comuns são 016 e 0 18, responsáveis por cerca de $70 \%$ dos casos de câncer de colo uterino. 0s HPV 6 e 11, encontrados em $90 \%$ dos condilomas genitais e papilomas laríngeos, são considerados não oncogênicos ${ }^{2}$.

No mundo, estima-se que $80 \%$ das mulheres sexualmente ativas serão infectadas pelo HPV em algum momento de sua vida, podendo ser mais frequente nos homens. Acredita-se que entre $25 \%$ e $50 \%$ da população feminina e $50 \%$ da população masculina esteja infectada pelo HPV. Porém, a maioria das infecções é transitória, sendo combatida espontaneamente pelo sistema imune e regredindo entre 6 meses e 2 anos após a exposição².

Diante desse cenário, a Organização Mundial da Saúde (OMS) preconiza a vacina contra o HPV como um dos métodos profiláticos mais eficazes para reduzir a infecção pelo vírus. Atualmente, a vacina adotada pelo Ministério da Saúde (MS) e ofertada pelo Sistema Único de Saúde (SUS) é a quadrivalente, que protege contra os tipos $6,11,16$ e 18 do HPV, sendo indicada para meninas de 9 a 14 anos e meninos de 11 a 14 anos, pessoas convivendo com o vírus da imunodeficiência humana (human immunodeficiency virus [HIV]) e pessoas transplantadas com idades entre 9 e 26 anos. Essa vacinação profilática não atua no tratamento do HPV, pois não demonstra eficácia contra infecções ou lesões já existentes ${ }^{3}$.

A vacina contra o HPV tem como alvo crianças e adolescentes por apresentar maior evidência de proteção e indicação para pessoas que ainda não 
têm vida sexual ativa, partindo do pressuposto de que nunca houve contato com 0 agente infeccioso ${ }^{3}$. Contudo, a vacina foi nota discordante durante as campanhas pela resistência de parte de diversos públicos. A campanha partiu do argumento de que o HPV é disseminado pelo contato sexual, obtendo uma prevenção mais eficaz mediante a vacinação de adolescentes antes do início da atividade sexual, gerando controvérsias ${ }^{4}$.

Sob essa ótica, percebe-se a necessidade de assegurar aos pais de adolescentes a confiabilidade das informações obtidas e proporcionar espaços de diálogo para o esclarecimento de dúvidas acerca da infecção e vacinação contra o HPV, sem desconsiderar seu conhecimento prévio e as questões socioculturais envolvidas nesse panorama.

Assim, este estudo teve por objetivo identificar o conhecimento dos pais de adolescentes sobre a vacinação contra o HPV.

\section{METODOLOGIA}

Trata-se de pesquisa qualitativa, exploratóriodescritiva. 0 método da pesquisa qualitativa se aplica ao estudo da história, das relações, das representações e das percepções, apresentando melhor conformação a investigações de grupos e segmentos delimitados e focalizados, de histórias sociais sob a ótica dos atores, de relações e de discursos e documentos ${ }^{5}$. Já a pesquisa exploratório-descritiva descreve as características de determinada população ou fenômeno, buscando maior familiaridade com o objeto do estudo para esclarecimento ou constituição de hipóteses ${ }^{6}$.

$0 s$ participantes do estudo foram 10 pais de adolescentes em idade de vacinação contra o HPV, usuários da Estratégia Saúde da Família (ESF) de um município do extremo oeste catarinense. 0s critérios de inclusão foram: ser pais de adolescentes do sexo feminino em idade de vacinação contra o HPV; e pertencer à área de abrangência da ESF. Entrou-se em contato com a equipe da ESF e as planilhas com os nomes dos indivíduos elegíveis para a pesquisa foram consultadas para gerar a lista de possiveis participantes segundo os critérios de inclusão.

Vale ressaltar que, no período de realização desta pesquisa, apenas as adolescentes eram incluídas na campanha de vacinação contra o HPV. 0 s adolescentes passaram a receber a vacina no ano seguinte.

A coleta de dados ocorreu em outubro de 2016, por meio de entrevista semiestruturada, com perguntas

\section{...a Organização \\ Mundial da Saúde (OMS) \\ preconiza a vacina contra \\ o HPV como um dos \\ métodos profiláticos mais \\ eficazes para reduzir a infecção pelo vírus.}

abertas, permitindo aos participantes discorrer sobre seu conhecimento da infecção pelo HPV, bem como seu conhecimento e sua opinião acerca da vacinação disponibilizada pelo SUS. As entrevistas tiveram caráter individual, sendo conduzidas em espaço que garantisse a privacidade de cada participante. A gravação em aparelho digital contou com o consentimento dos participantes. Todas as entrevistas foram transcritas na íntegra.

Os dados foram submetidos a Análise de Conteúdo do tipo temática proposta por Minayo ${ }^{5}$, que parte de uma leitura em primeiro plano dos documentos para atingir um nível mais profundo, ultrapassando os sentidos manifestos no material. Tal análise engloba um conjunto de técnicas de pesquisa que permitem inferir achados em determinado contexto, mediante a organização, leitura e discussão dos dados coletados 5 .

A análise temática teve 3 etapas: a) organização dos dados - identificação do material, leitura inicial e primeiras impressões dos dados obtidos; b) classificação dos dados - a partir das questões elaboradas houve seleção dos trechos mais relevantes e das ideias centrais, agrupados em categorias empíricas (para este agrupamento se considerou a relevância da fala acerca do objeto, a recorrência do tema e a expressividade); e c) análise e interpretação final - movimento entre os conteúdos teóricos e empíricos, correlacionando-os de modo dialético.

Cumprindo todos os preceitos da Resolução n. 466/2012, do Conselho Nacional de Saúde $(\mathrm{CNS})^{7}$, 0 estudo foi aprovado pelo Comitê de Ética em Pesquisa da Universidade do 0este de Santa Catarina (UNOESC), sob o Certificado de Apresentação para Apreciação Ética (CAAE) n. 57540116.3.0000.5367 e o Parecer n. 1.755.820. 0 anonimato dos participantes foi preservado mediante código alfanumérico das falas (letra "E", de entrevistado, seguida pela numeração das entrevistas - E1 a E10). 


\section{RESULTADOS E DISCUSSÃO}

Do total de 10 pais de adolescentes incluídos no estudo, 9 eram do sexo feminino e 1 do sexo masculino, com idades entre 30 e 53 anos. Em relação à escolaridade, 6 participantes apresentaram Ensino Fundamental incompleto, 1 tinha Ensino Fundamental completo, 2 tinham Ensino Médio incompleto e 1 tinha Ensino Médio completo.

Quanto à cor da pele, 6 se declararam brancos, 3 pardos e 1 preto.

Quando questionados sobre o que sabem acerca do HPV, os participantes disseram que se trata de uma DST, podendo ser transmitida via relações sexuais desprotegidas, e associam a infecção ao aparecimento de verrugas - principal característica do HPV. Alguns dos entrevistados traçam uma relação entre o HPV e o câncer de colo uterino, demonstrando ter consciência da gravidade do vírus e das consequências que ele pode ocasionar:

[...] é uma doença transmitida pelo homem para a mulher, mas que dá na mulher, no colo do útero [...] É uma verruga que pode dar no corpo inteiro. (E5)

É tipo um câncer transmissivel, que pega através do ato sexual. (E8)

É um vírus sexualmente transmissivel [...] que no colo do útero se torna câncer. (E10)

Apesar de serem consideradas benignas, as verrugas do HPV passaram a ser relevantes após a confirmação de sua relação com o câncer de colo uterino, estando presente em $94 \%$ dos casos do carcinoma. Tal relação representa um problema de saúde pública, visto que, depois do câncer de mama, trata-se de uma das principais causas de mortalidade feminina, sendo a população masculina a principal responsável por sua transmissã $0^{8}$. Entretanto, outros fatores de risco podem estar associados,

\section{...os entrevistados apresentam conhecimento de que a vacinação tem $o$ objetivo de prevenir a infecção por HPV...}

como número de parceiros sexuais, início precoce da atividade sexual, história de outras DST, tabagismo e uso de contraceptivo oral ${ }^{9}$.

Embora as informações sejam limitadas, os entrevistados apresentam conhecimento de que a vacinação tem o objetivo de prevenir a infecção por HPV e, consequentemente, a evolução para o câncer de colo uterino. Eles acreditam que, ao tomar a vacina, a adolescente estará livre do risco de desenvolver a doença no futuro:

Essa vacina do HPV previne muitas doenças [...] É um problema que se você não fizer o tratamento certo " $t u$ " vai perder ele [o útero] [...] Ela previne a doença do câncer.

Eu sei que a vacina é para prevenir a doença [...] 0 HPV é aquela vacina que as meninas [filhas] fizeram injeção, "né"? (E4)

[...] É importante fazer para prevenir a doença, que seria tipo o câncer do colo do útero [...] Com a vacina estaria prevenindo. (E8)

A vacina do HPV surgiu com o propósito de prevenção contra a infecção e diminuição do número de pacientes que possam ser acometidas pelo câncer de colo uterino, sendo que muitas pessoas fazem referência à vacinação como forma de prevenir o carcinoma 4 . A vacinação profilática traz a possibilidade de ampliar as estratégias preventivas para a população suscetível à infecção e interferir na incidência do carcinoma9 .

Pensando nisso, essa vacina foi incorporada à carteira de vacinação em 2014, com vistas a prevenir o câncer de colo uterino. Em um primeiro momento, apenas as meninas faziam parte do público a ser vacinado. Atualmente, o MS preconiza que sejam vacinadas as meninas de 9 a 14 anos e os meninos de 11 a 14 anos, com um esquema de 2 doses a serem administradas em um intervalo de 6 meses $^{8}$. As campanhas para a divulgação e realização da vacina enfatizaram a prevenção do câncer como forma de alertar e transmitir a ideia de que o câncer de colo uterino pode afetar todas as mulheres ${ }^{4}$.

Percebe-se, pelos depoimentos, que alguns participantes pouco sabem sobre a vacinação contra o HPV, demonstrando insegurança e dúvida ao falar no assunto. Referem que ouviram sobre a vacina por meio das filhas e da escola, mas que até então desconheciam sua existência e continuam não 
sabendo exatamente qual é sua indicação:

Não conheço, só minhas meninas fizeram ela [...] Saiu no colégio, aí elas pediram o que eu achava, eu falei: "Se é para o bem da saúde, vamos lá!" (E1)

Sobre a vacina, eu não sei nada. (E2)

Eu, na verdade, não conheço. Agora que eu estava vendo porque veio lá na escola. Não sabia que existia. (E9)

Ainda há desconhecimento, aliado a informações superficiais, sobre a vacina, tanto do público-alvo da vacinação quanto de seus responsáveis, podendo ser associado à similaridade nas fontes de informações em relação ao vírus e à vacina ${ }^{10}$. A preocupação em torno disso recai sobre a baixa adesão do públicoalvo à imunização. Nota-se em alguns estudos que o desconhecimento da existência da vacina, bem como a falta de informações concretas e claras sobre sua indicação, estão entre os principais motivos de sua recusa. Outros motivos apontados para a recusa da vacina são: a) dúvidas quanto à sua eficácia; b) medo de possiveis efeitos colaterais; c) indução à iniciação sexual precoce; e d) crença de que o exame citopatológico seja suficiente para a prevenção do HPV ${ }^{11,12}$.

Partindo da necessidade de levantar maiores informações sobre a vacina contra o HPV, ressaltase a importância de investir em ações e estratégias de educação em saúde para que se alcance a meta desejada. Faz-se necessário o esclarecimento acerca da necessidade da vacinação e de todos os aspectos que a envolvem, além de mostrar outros meios de prevenção contra o HPV, como o uso de preservativos e o acompanhamento via exame citopatológico. Esse entendimento deve voltar-se tanto aos adolescentes quanto aos seus responsáveis ${ }^{12}$.

Quando questionados sobre sua opinião quanto à vacinação contra o HPV, todos os entrevistados relataram ser a favor da vacina, considerada algo que contribui para a saúde das crianças e dos adolescentes:

É uma boa ideia [...] Eu acho que se é para prevenir, tem que ter. Eu deixei as minhas [filhas] fazerem. (E1)

[...] É bom que previne [...] Porque é uma coisa que é para a saúde, é um cuidado da saúde. (E3)

Eu sou a favor, porque eu também tenho duas filhas e a prevenção é o que vale. (E6) Eu acho ótimo, na minha época não tinha isso. (E8)

0 papel dos pais na decisão relativa à vacinação de seus filhos é fundamental, constituindo um fator de estímulo à vacinação, visto que inicialmente já existe boa aceitação por parte da população, promovendo enormes benefícios para a saúde pública. Dentre as justificativas mais usadas para apoiar a vacina se encontra a possibilidade de prevenção do câncer de colo uterino, o que reforça a necessidade e a importância da imunizaçã $0^{13}$.

Alguns participantes sabem que a vacinação contra - HPV apresenta maior eficácia quando aplicada antes do início da atividade sexual, adquirindo-se melhor resposta imune. Tal fato é confirmado pela literatura, pois as vacinas vêm se mostrando mais efetivas quando administradas antes do início da vida sexual, e também pelas campanhas de vacinação propostas pelo MS, que têm como público-alvo os adolescentes e pré-adolescentes:

Eu sei que a vacina só pode ser dada nas meninas que são virgens ainda. (E5)

Sobre a vacina, só sei que dão para as crianças, as meninas. Que isso eles dão preventivo antes de ficarem moça e quererem sair. (E6)

A vacina administrada em meninas alcança maior eficácia sem apresentar eventos adversos graves. Como a infecção é adquirida após o início da vida sexual, a vacina é recomendada para mulheres que ainda não passaram por essa experiência. As adolescentes que não foram infectadas e expostas ao vírus terão maiores benefícios. Após o primeiro contato sexual há aumento da probabilidade da aquisição da infecção pelo HPV ${ }^{14}$.

As mulheres que já iniciaram sua vida sexual também podem tomar a vacina. Ela não altera o curso

\section{0 papel dos pais na decisão relativa à vacinação de seus filhos é fundamental...}


da doença preexistente, mas contribui para proteger a mulher das cepas às quais ainda não foi exposta. Além disso, para as mulheres com vida sexual ativa se orienta a realização periódica do exame citopatológico, a fim de investigar um possivel contato com o vírus do HPV, evitando a progressão para uma doença mais grave, como o câncer de colo uterino.

Dois entrevistados levantaram a questão do incentivo às relações sexuais que a vacinação contra - HPV acabou gerando em parte da população, mas eles se posicionaram contra essa ideia:

Muitos falam que incentiva a criança para o negócio do sexo. Não é isso, é uma doença que você está evitando. Que têm muitos pais e mães que não levam [os filhos para vacinar] porque eles têm medo de incentivar o filho. Mas não é, é uma prevenção que eles têm para a saúde deles mais tarde. (E3)

[...] Como têm pais que não queriam que as crianças sejam vacinadas, por causa que têm medo que vão fazer relação sexual. Como a minha menina foi tomar a vacina na escola, alguns pais que foram junto eram contra essa vacina. (E10)

Houve inúmeras críticas quanto à vacinação contra o HPV, principalmente relativas ao tema sexualidade das crianças e dos adolescentes. Para muitos, a vacina não era vista como uma tecnologia para a prevenção do HPV, mas como uma imposição do Estado que gerava implicações duvidosas no comportamento dos adolescentes, um suposto incentivo à iniciação sexual ${ }^{4}$.

A falta de conhecimento dos pais a respeito do vírus, a dificuldade que eles apresentam para abordar assuntos relacionados à sexualidade com os filhos adolescentes e o medo de que, ao receberem a vacina, os filhos possam iniciar precocemente sua vida sexual levam à negação de muitos pais em vacinar seus filhos ${ }^{11,12}$. Tais pensamentos criam um obstáculo para que os adolescentes busquem a prevenção contra o HPV, reafirmando a necessidade de maiores orientações sobre a vacina, com vistas a desconstruir mitos e paradigmas relacionados à sua aplicação. A falta de orientação adequada a respeito do HPV favorece as concepções inadequadas ${ }^{15}$.

Quanto à origem das informações sobre a vacinação, os depoimentos indicam que ele foi adquirido de diversas fontes: a) profissionais da

\section{...ressalta se \\ a importância de investir em ações e estratégias de educação em saúde...}

saúde; b) membros da comunidade escolar; c) mídia etc. Dentre os profissionais da saúde, o mais citado foi o agente comunitário de saúde (ACS):

Eu recebi da agente de saúde [...] Ela explicou
sobre a vacina. Orientou que era contra essas
doenças. (E1)
[...] a agente de saúde que me falou algumas
coisas sobre a vacina. (E4)

0 ACS desempenha o papel de integrador entre a comunidade e a ESF, representando a equipe de saúde junto à população. Todavia, faz-se necessário definir seu papel de modo mais claro, para que as ações não abranjam somente situações pontuais. 0 ACS pode trabalhar com educação e promoção da saúde por meio de orientações sobre os cuidados de saúde. Mostra-se pertinente permitir que haja maior espaço de debate e trocas com toda a equipe de saúde, para que sua atuação se torne mais qualificada e efetiva na comunidade ${ }^{16}$.

0 enfermeiro foi outro profissional da saúde mencionado pelos participantes. 0 HPV é uma doença que requer mudanças de comportamento, principalmente as voltadas a práticas sexuais seguras, e o enfermeiro assume um papel fundamental nesse processo de prevenção, detecção e rastreamento de doenças:

[...] a enfermeira conversou [...] Pela minha preocupação de vacinar a [filha]. (E5)

Com a enfermeira mesmo, no posto aqui no bairro. (E7)

A descoberta precoce da infecção pelo HPV, bem como as medidas de prevenção primária para o controle da transmissão, pode ser legitimada pelo trabalho eficaz da equipe de enfermagem. Nesse momento, o enfermeiro deve adotar atitudes 


\section{$A$ escola surge \\ como um espaço privilegiado \\ para a promoção \\ de saúde...}

proativas, com estímulo à adesão de ações preventivas (como a vacina). É importante proporcionar espaços de diálogo quando os usuários têm contato com as equipes da ESF, de modo a potencializar o papel da educação em saúde. Nesse contexto, a consulta de enfermagem se caracteriza como uma estratégia tecnológica de cuidado eficaz, resolutiva, respaldada por lei e privativa do enfermeiro, que proporciona inúmeras vantagens à assistência ofertada e auxilia a promoção da saúde, o diagnóstico e o tratamento precoce, além da prevenção de situações evitáveis ${ }^{17}$.

A escola também foi referenciada como um dos locais onde os pais receberam informações sobre a vacina. Ela aparece como uma importante disseminadora de informações e transformadora da realidade, assumindo uma responsabilidade social ao tratar de assuntos que envolvam a sexualidade, incluindo nessa discussão toda a comunidade escolar, inclusive os pais:

Colégio que avisou que ia ter essa vacina. (E3)

Elas [filhas] trouxeram o bilhete do colégio dizendo da vacina. (E6)

[...] no colégio tiveram palestra e tiveram para fazer a vacina. (E8)

A escola surge como um espaço privilegiado para a promoção de saúde em um enfoque ampliado, facilitando as oportunidades de trocas por meio do convívio social. Construir espaços de diálogo entre adolescentes, professores, profissionais da saúde e comunidade é um importante dispositivo para construir uma resposta social visando à superação das relações de vulnerabilidade entre os adolescentes. No contexto escolar, as práticas educativas favorecem reflexões e discussões que ampliam o campo de conhecimento ao abordar questões de seu cotidiano, como sexualidade e saúde preventiva, contribuindo efetivamente para escolhas conscientes no desenvolvimento de práticas seguras ${ }^{18}$.

Outras fontes de informações mencionadas foram os meios de comunicação, principalmente a televisão e o rádio. A mídia se configura como propagadora de informações, contribuindo para a divulgação de campanhas criadas pelo MS. 0 que gera preocupação é a veracidade e concretude das informações repassadas à população:

Que nem na televisão explicou que tinha que fazer essa vacina. (E2)

[...] eu escutei através do rádio também, dessa vacina que ia ter. (E3)

[...] Eu assisti na televisão. (E8)

Para corroborar esse achado, alguns estudos evidenciam os meios de comunicação, principalmente a televisão, como fontes preferenciais de informação acerca da vacinação contra $0 \mathrm{HPV}^{19}$. A fim de encontrar justificativas para o desconhecimento ou a superficialidade das informações sobre 0 HPV, percebe-se a informalidade das fontes de informações, com destaque para a mídia, e seu afastamento dos elementos promotores da saúde. Encontrando-se o profissional da saúde distante enquanto provedor de práticas preventivas e não apenas curativas, a população se sente estimulada a buscar respostas em outros meios menos confiáveis. Quando o profissional da saúde assume maior compromisso com a educação e a promoção da saúde, o esclarecimento se torna uma prática prevalente e aumenta a adesão dos usuários aos recursos dos serviços de saúde ${ }^{10}$.

\section{CONCLUSÃO}

Constatou-se que o conhecimento dos pais de adolescentes em relação à vacinação contra o HPV ainda é insuficiente, marcado por conceitos superficiais tanto sobre a infecção quanto acerca da vacina. Apesar disso, os entrevistados apoiam a vacinação como medida de prevenção primária ao HPV e consideram essa medida algo positivo para a saúde das crianças e dos adolescentes, principalmente devido à relação entre o HPV e o câncer de colo uterino.

Evidencia-se a importância de investir em ações de educação em saúde, considerando que esta assume um papel modificador na realidade de saúde da população e constitui estratégia fundamental para o sucesso das campanhas de vacinação contra o 
HPV, com vistas a reduzir a infecção e a transmissão pelo vírus e, consequentemente, a morbimortalidade de mulheres pelo câncer de colo uterino.

Espera-se que este estudo contribua no sentido de suscitar futuras reflexões sobre o tema, além de auxiliar os profissionais da saúde a revisar e legitimar suas práticas educativas, haja vista a conscientização dos adolescentes diante dos riscos de práticas sexuais inseguras e das consequências que estas podem acarretar. Sugere-se a realização de pesquisas com abordagem qualitativa - ainda escassas na literatura sobre o tema.

\section{CONTRIBUIÇÃO DAS AUTORAS}

Camila Amthauer contribuiu com o delineamento do estudo e a redação e revisão crítica do manuscrito. Cladiane dos Santos contribuiu com a realização da pesquisa, o delineamento do estudo e a redação do manuscrito.

\section{REFERÊNCIAS}

1. Boiron L, Joura E, Largeron N, Prager B, Uhart M. Estimating the cost-effectiveness profile of a universal vaccination programme with a nine-valent HPV vaccine in Austria. BMC Infect Dis. $2016 ;(16): 153$. https://pubmed.ncbi.nlm.nih.gov/27084683/

2. Instituto Nacional do Câncer. 0 que significa HPV? Rio de Janeiro: INCA; 2019.

3. Brasil. Informe técnico sobre a vacina papilomavírus humano (HPV) na atenção básica. Brasília (DF): Ministério da Saúde; 2014.

4. Quevedo JP, Inácio $M$, Wieczorkievicz AM, Invernizzi N. A política de vacinação contra o HPV no Brasil: a comunicação pública oficial e midiática face à emergência de controvérsias. Revista Tecnologia e Sociedade [serial on the internet]. 2016 [cited 2020 Jun 18];12(24):1-26. Available from: https:// periodicos.utfpr.edu.br/rts/article/view/3206/2622

5. Minayo MCS. 0 desafio do conhecimento: pesquisa qualitativa em saúde. São Paulo: Hucitec; 2014.

6. Gil AC. Como elaborar projetos de pesquisa. São Paulo: Atlas; 2010.

7. Brasil. Resolução n. 466, de 12 de dezembro de 2012. Brasília (DF): Conselho Nacional de Saúde; 2012.

8. Ramos ASMB, Leal LRF, Almeida HFR, Lima FF, Souza IBJ, Rocha FCG. Papilomavírus humano: fatores que interferem na adesão dos adolescentes à vacinação. Revista Interdisciplinar [serial on the internet]. 2018 [cited 2020 Jun 10];11(3):114-22. Available from: https://dialnet.unirioja.es/servlet/ articulo? codig $0=6763763$

9. Silveira BJ, Dal Moro VC, Silveira MB, Espírito Santo LR, Prince KA. Adesão à imunização contra o papilomavírus humano na saúde pública do Brasil. Rev Saúde Pública Paraná [serial on the internet]. 2017 [cited 2020 Jun 17];18(1):157-64. Available from: http://168-194-69-20.wsutech.com/index. php/espacosaude/article/view/356/pdf

10. Pereira RGV, Machado JLM, Machado VM, Mutran TJ, Santos LS, Oliveira, et al. A influência do conhecimento na atitude frente à vacina contra o papilomavírus humano: ensaio clínico randomizado. ABCS Health Sci [serial on the internet]. 2016 [cited 2016 0ct 17];41(2):78-83. Available from: https://www.portalnepas.org.br/ abcshs/article/view/873/738

11. Zanini NV, Prado BS, Hendges RC, Santos CA, Callegari FVR, Bernuci MP. Motivos para recusa da vacina contra o papilomavírus humano entre adolescentes de 11 a 14 anos no Município de Maringá-PR. Rev Bras Med Fam Comunidade [serial on the internet]. 2017 [cited 20160 ct 31];12(39):1-13. Available from: https://www.rbmfc.org.br/rbmfc/ article/view/1253/861

12. França SB, Silva RAR, Cardoso JS, Soares ACJ, Faria AKS. Adesão das adolescentes à campanha de vacinação contra o papiloma vírus humano: no Brasil, Minas Gerais e microrregião da Serra Geral. Unimontes Científica [serial on the internet]. 2017 [cited 2020 Jul 17];19(1):2-12. Available from: http://www. ruc.unimontes.br/index.php/unicientifica/article/ view $/ 505 / 386$

13. Osis MJD, Duarte GA, Sousa MH. Conhecimento e atitude de usuários do SUS sobre o HPV e as vacinas disponiveis no Brasil. Rev Saúde Pública [serial on the internet]. 2014 [cited 2020 Jun 20];48(1):12333. Available from: https://www.scielo.br/pdf/rsp/ v48n1/0034-8910-rsp-48-01-0123.pdf

14. Borsatto AZ, Vidal MLB, Rocha RCNP. Vacina contra - HPV e a prevenção do câncer do colo do útero: subsídios para a prática. Rev Bras Cancerol [serial on the internet]. 2011 [cited 2020 Jul 3];57(1):67-74. Available from: http://www1.inca.gov.br/rbc/n 57/ $\mathrm{v} 01 / \mathrm{pdf} / 10$ revisao de literatura vacina hpv prevencao cancer colo utero subsidios.pdf

15. Pereira MJM, Silva MHF, Gomes LM, Lino HA. Pesquisa com mulheres portadoras do papilomavírus humano (HPV): a experiência viva dos preconceitos, tabus e crenças. Revista Científica da Faculdade de Medicina de Campos [serial on the internet]. 2017 [cited 2020 Jul 17];12(1):15-21. Available from: http://www.fmc.br/ojs/index.php/RCFMC/article/ view $/ 163 / 137$ 
16. Machado LM, Mattos KM, Colomé JS, Freitas NQ, Sangoi TP. Estratégia Saúde da Família: a percepção do agente comunitário de saúde quanto à sua atuação. Ciênc Cuid Saúde [serial on the internet]. 2015 [cited 2020 Jun 20];14(2):1105-12. Available from: http://periodicos.uem.br/ojs/index.php/ CiencCuidSaude/article/view/22612/pdf 360

17. Souza SV, Ponte KMA, Araújo Júnior DG. Prevenção do HPV nas mulheres: estratégia adotada por enfermeiros na atenção primária à saúde. Sanare (Sobral, 0nline) [serial on the internet]. 2015 [cited $2020 \mathrm{Jul} 19] ; 14(1): 46-51$. Available from: https://sanare.emnuvens.com.br/sanare/article/ view $/ 607 / 324$

18. Nothaft SCS, Zanatta ZA, Brumm MLB, Galli KSB, Erdtmann BK, Buss E, et al. Sexualidade do adolescente no discurso de educadores: possibilidades para práticas educativas. REME Rev Min Enferm [serial on the internet]. 2014 [cited 2020 Jul 19];18(2):2849. Available from: https://cdn.publisher.gn1.link/ reme.org.br/pdf/v18n2a03.pdf

19. França MCA, França MCS, Moraes SDS. Conhecimento de mulheres acerca do papilomavírus humano e sua relação com o câncer de colo uterino. Cogitare Enferm [serial on the internet]. 2013 [cited 2016 0ct 17];18(3):509-14. Available from: https:// revistas.ufpr.br/cogitare/article/view/33564/21062

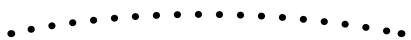

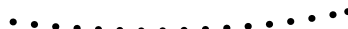
$0^{\circ}$ $\ldots \ldots \ldots \ldots \ldots \ldots \ldots \ldots$

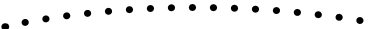

$\ldots \ldots \ldots$

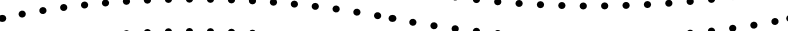
$\ldots \ldots \ldots \ldots \ldots \ldots \ldots \ldots \ldots$ $\ldots \ldots \ldots \ldots \ldots \ldots$ $\ldots \ldots \ldots \ldots \ldots \ldots \ldots \ldots \ldots \ldots$ $\ldots \ldots \ldots \ldots \ldots \ldots \ldots \ldots \ldots \ldots \ldots$
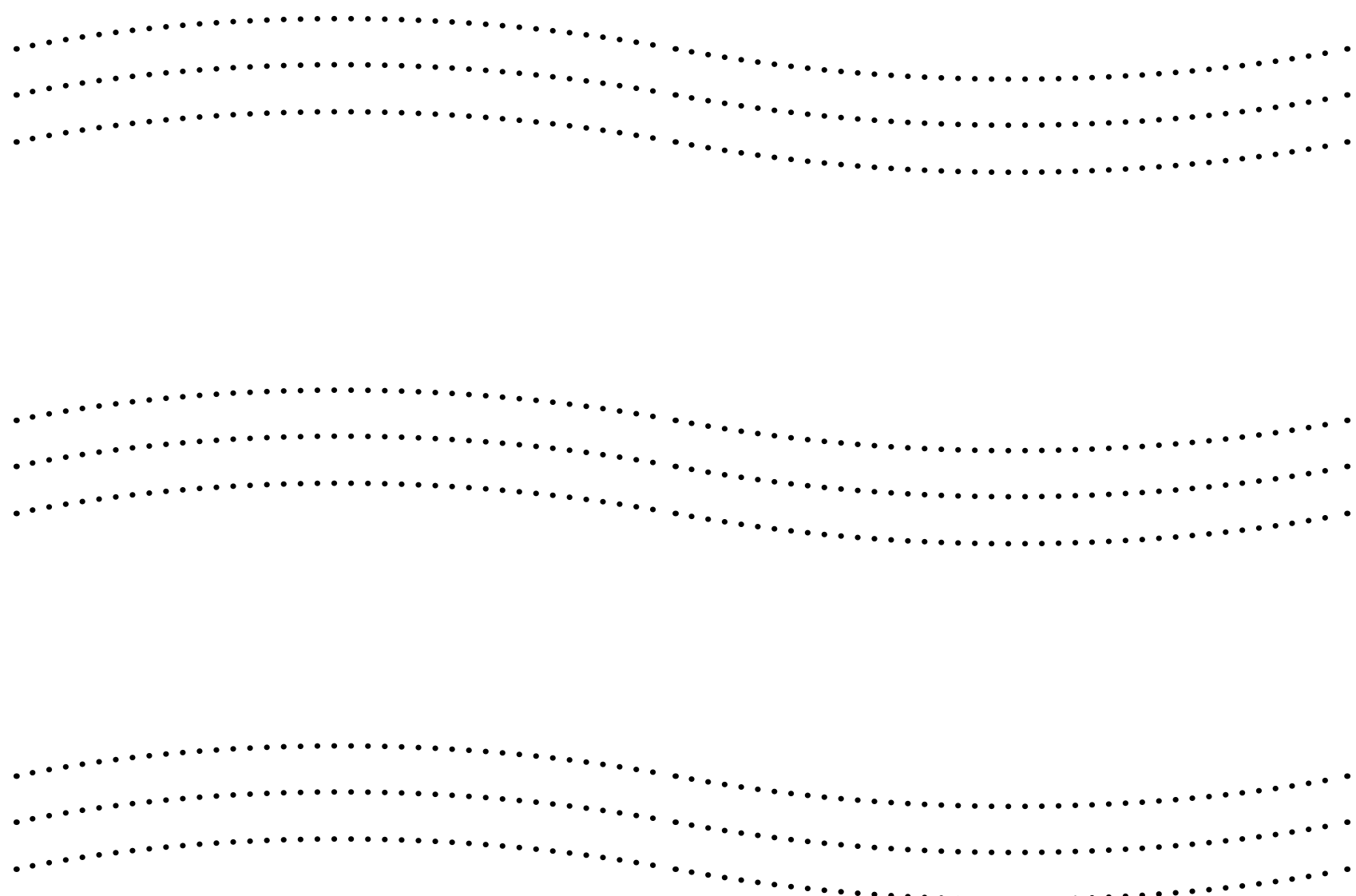